\title{
Lower Serum Tropomyosin Receptor Kinase B Levels in Patients with Schizophrenia
}

\author{
Yi-Yung Hung, Tiao-Lai Huang
}

Background: Brain-derived neurotrophic factor (BDNF) and tropomyosin receptor kinase $\mathrm{B}$ (TrkB) have previously been found to be reduced in the prefrontal cortex of patients with schizophrenia. In this study, we tried to investigate the protein levels of BDNF and TrkB from peripheral blood in the veins of individuals with schizophrenia and health controls.

Methods: $\quad$ From January 2008 to November 2010, we recruited 40 schizophrenic patients and 56 healthy controls. Serum BDNF and total TrkB protein levels were detected with enzyme-linked immunosorbent assay (ELISA) kits. Outliners of BDNF and TrkB were excluded initially. Analysis of covariance (ANCOVA) with age adjustment was used for group mean differences of different groups.

Results: After using the ANCOVA with age adjustment, the results

\section{At a Glance Commentary}

Scientific background of the subject

Although Brain-derived neurotrophic factor (BDNF) and tropomyosin receptor kinase B (TrkB) have been found to be associated with schizophrenia in central nerve system, there is few data in the published literature regarding the changes in peripheral blood.

\section{What this study adds to the field}

Lower TrkB protein level is found in patients with schizophrenia especially in female. of this work showed that BDNF presented no significant difference $(\mathrm{F}=0.065, p=0.800)$, but the serum TrkB protein level was significantly lower in schizophrenic patients than in healthy controls $(\mathrm{F}=8.34, p=0.005)$.

Conclusion: Our findings showed a lower TrkB protein level in serum from schizophrenia patients compared with healthy controls, indicating that the signaling transmission of BDNF/TrkB may be affected in peripheral blood from individuals with schizophrenia.

(Biomed J 2013;36:132-136)

Key words: brain-derived neurotrophic factor, schizophrenia, tropomyosin receptor kinase $B$

$\mathrm{S}_{\mathrm{d}}^{\mathrm{c}}$ chizophrenia is thought to be a chronic, severe, and disabling brain disease. However, its neuropathological basis remains unclear. ${ }^{[1]}$ Some evidence has suggested that the pathogenesis of schizophrenia is neuro-developmental impairments, especially in brain-derived neurotrophic factor (BDNF), a member of the neurotrophin family. ${ }^{[2]}$ Besides, BDNF in serum was identified as one of the biological signatures for schizophrenia. ${ }^{[3,4]}$ The role of BDNF in schizophrenia has been extensively investigated in different stages of the disease, including the effect of antipsychotic drug treatment. ${ }^{[5,6]}$ Postmortem studies of the central nervous system have shown that BDNF protein levels, as measured by enzyme-linked immunosorbent assay (ELISA), were increased in cortical areas and decreased in the hippocampus in schizophrenia; ${ }^{[7]}$ however, immunohistochemical studies have shown increased expression of BDNF ${ }^{[8]}$ Several studies have reported a reduction of BDNF in peripheral blood in chronic and relapsed schizophrenia patients. ${ }^{[2,9,10]}$

On the other hand, the tropomyosin receptor kinase B (TrkB), a receptor of BDNF on cell membrane, is implicated in the neuropathology of schizophrenia and other psychiatric diseases. ${ }^{[11]}$ The level of expression of TrkB in the brain of subjects with schizophrenia is still inconclusive. In one postmortem study, the expressions of TrkB

From the Department of Psychiatry, Kaohsiung Chang Gung Memorial Hospital and Chang Gung University College of Medicine, Kaohsiung, Taiwan

Received: Apr. 25, 2012; Accepted: Jul. 16, 2012

Correspondence to: Dr. Tiao-Lai Huang, Department of Psychiatry, Kaohsiung Chang Gung Memorial Hospital and Chang Gung University College of Medicine, Kaohsiung, Taiwan. 123, Dapi Rd., Niaosong, Kaohsiung 833, Taiwan (R.O.C.). Tel: 886-7-7317123 ext. 8753; Fax: 886-7-7326817; E-mail: a540520@adm.cgmh.org.tw

DOI: $10.4103 / 2319-4170.113229$ 
receptor were reduced significantly in the hippocampus and the prefrontal cortex. ${ }^{[12]}$ However, other studies have reported increased TrkB-positive neurons in the hippocampus of subjects with schizophrenia. ${ }^{[8]}$ When comparing BDNF and TrkB mRNA levels in the prefrontal cortex of 15 pairs of subjects with schizophrenia and matched control subjects, as assessed by in situ hybridization, one study found a significant decrease in the prefrontal cortex of subjects with schizophrenia. ${ }^{[13]}$ In addition, a diminished expression of TrkB mRNA in large neurons, but not in small neurons, was reported in the dorsolateral prefrontal cortex in patients with schizophrenia. ${ }^{[14]} \mathrm{A}$ TrkB protein level elevation in peripheral blood was reported previously in patients with major depression, ${ }^{[15]}$ but there is still no data on subjects with schizophrenia. Therefore, we assumed that BDNF/TrkB signal pathway might be involved in schizophrenia and sought to investigate the BDNF/TrkB protein level in peripheral blood of schizophrenia patients.

\section{METHODS}

\section{Subjects}

Serum BDNF and TrkB protein levels in acute exacerbated schizophrenic outpatients or inpatients and healthy controls were collected from January 2008 to November 2010 at Chang Gung memorial hospital (CGMH)-Kaohsiung medical center, Taiwan. Institutional Review Board (IRB) approval was obtained from the CGMH Ethics Committee. The structured clinical interview for DSM-IV Axis I Disorders (SCID-1) was used by a psychiatrist to diagnose schizophrenia. ${ }^{[16]}$ Psychopathology was assessed with the positive and negative syndrome scale (PANSS) for schizophrenia by the same psychiatrist. ${ }^{[17]}$

Voluntary healthy controls were enrolled from the medical staff and students. These healthy controls had neither a personal history nor a first-degree family history of psychiatric disorder. The Chinese health questionnaire-12 was used to assess the healthy control group by the same psychiatrist, to exclude psychiatric diseases based on diagnostic and statistical manual of mental disorders, Fourth Edition (DSM-IV) criteria ${ }^{[18]}$ The questionnaire was derived from a Chinese translation of the general health questionnaire, with the addition of specially designed, culturally relevant items.

None of the participants had an acute or chronic physical illness, including heart, lung, liver, kidney, or metabolic diseases. No medication was taken for at least 1 week before entering the study. After the demographic data was collected, patient group was treated with antipsychotic drugs.

\section{Laboratory data}

Venous blood $(5 \mathrm{ml})$ samples were drawn into plain tubes between 08.00 and 10.00 a.m., before the patients had eaten breakfast. The serum samples were separated in a centrifuge at $1500 \mathrm{rpm}$ and stored in a $80 \mathrm{C}$ refrigerator quickly until assayed in 3 months. Serum BDNF and total TrkB protein levels were detected with ELISA kits (BDNF Emax Immunoassay System, Promega Co., Madison, WI, USA; The Human Total TrkB DuoSet IC ELISA, R\&D Systems, Inc., Minneapolis, MN, USA). Absorbencies were measured by microtiter plate reader (absorbency at $450 \mathrm{~nm}$ ). The BDNF assay detects a minimum of $15.6 \mathrm{pg} /$ $\mathrm{ml}$ of BDNF and shows less than 3\% cross-reactivity with other related neurotrophic factors (Nerve growth factor (NGF), Neurotrophin-3 (NT-3), and Neurotrophin-4 (NT-4)) at $100 \mathrm{ng} / \mathrm{ml}$. The TrkB assay is as sensitive as immunoprecipitation (IP)-Western blot analysis and does not cross-react with TrkA or TrkC.

\section{Statistical analysis}

Outliners of BDNF and TrkB were excluded initially. Student's $t$-test was used to compare the continuous demographic data. Chi-square test was used to compare categorical data. BDNF and TrkB analyses were performed by using an analysis of covariance (ANCOVA) with age adjustment

Table 1: Demographics and serum BDNF protein levels in all participants after excluding outliners of BDNF

\begin{tabular}{lccc}
\hline & Schizophrenia & $\begin{array}{c}\text { Healthy } \\
\text { controls }\end{array}$ & $\begin{array}{c}\text { F and } \\
p \text { values }\end{array}$ \\
\hline Sex (M/F) & $14 / 21$ & $24 / 28$ & $p=0.570$ \\
Age (years) & $34.83 \pm 1.85$ & $31.15 \pm 0.79$ & $p=0.075$ \\
Male & $30.86 \pm 2.02$ & $29.58 \pm 1.37$ & $p=0.593$ \\
Female & $37.48 \pm 2.66$ & $32.50 \pm 0.83$ & $p=0.087$ \\
PANSS & $112.60 \pm 5.06$ & - & - \\
Male & $130.00 \pm 4.00$ & - & - \\
Female & $117.67 \pm 7.91$ & - & - \\
BMI & $22.55 \pm 0.78$ & $23.26 \pm 0.55$ & $p=0.447$ \\
Male & $24.62 \pm 1.53$ & $24.08 \pm 0.83$ & $p=0.736$ \\
Female & $21.67 \pm 0.68$ & $22.55 \pm 0.72$ & $p=0.183$ \\
Education (years) & 12.34 & & \\
Duration of illness (years) & $7.50 \pm 0.86$ & - & - \\
BDNF (ng/ml) & $3.73 \pm 0.17$ & $4.67 \pm 0.34$ & $\mathrm{~F}=0.065$ \\
& & & $p=0.800$ \\
Male & $3.89 \pm 0.32$ & $6.11 \pm 0.42$ & $\mathrm{~F}=0.019$ \\
& & & $p=0.89$ \\
Female & $3.61 \pm 0.19$ & $3.43 \pm 0.38$ & $\mathrm{~F}=0.027$ \\
& & & $p=0.871$ \\
\hline
\end{tabular}

Data are presented as mean \pm SD. Student's $t$-test was used to compare age, PANSS, and BMI. Chi-square test was used to compare sex. BDNF and TrkB analysis were performed by using an analysis of covariance (ANCOVA) with age adjustment. Abbreviations:

PANSS: Positive and negative syndrome scale; BDNF: Brain-derived neurotrophic factor; BMI: Body mass index 
for group mean differences of different groups. All statistical analyses were performed using SPSS, version 12 . For each test, $p<0.05$ was considered significant.

\section{RESULTS}

Our sample consisted of 40 schizophrenia patients and 56 healthy control subjects. Table 1 shows the demographic data and serum BDNF after excluding the outliner of BDNF. Table 2 shows the demographic data and serum TrkB after excluding the outliner of TrkB. The mean total PANSS score was $112.60 \pm 5.06$ in Table 1 and $122.30 \pm 4.67$ in Table 2. T here was no dif ference between the two groups with regard to demographic data. The medication prescribed before survey was either risperidone 4-6 mg or clozapine 100-300 mg. Using ANCOVA with age adjustment, no significant difference in the mean values of BDNF protein levels in the patients and controls was found $(\mathrm{F}=0.065$, $p=0.800)$. Neither males $(\mathrm{F}=0.19, p=0.89)$ nor females $(\mathrm{F}=0.027, p=0.871)$ presented significant difference in comparison with controls. The TrkB protein level was significantly lower in schizophrenia patients than in healthy controls $(\mathrm{F}=8.34, p=0.005)$. When analyses were done in different genders, the TrkB protein level was significantly lower in schizophrenia patients than in healthy controls, in women: $322.50 \pm 94.12 \mathrm{pg} / \mathrm{ml}$ and $609.80 \pm 96.07 \mathrm{pg} / \mathrm{ml}$ for

Table 2: Demographics and serum TrkB protein levels in all participants after excluding outliners of TrkB

\begin{tabular}{lccc}
\hline & Schizophrenia & $\begin{array}{c}\text { Healthy } \\
\text { controls }\end{array}$ & $\begin{array}{c}\text { F and } \\
p \text { value }\end{array}$ \\
\hline Sex (M/F) & $17 / 22$ & $21 / 32$ & $p=0.703$ \\
Age (years) & $34.50 \pm 1.60$ & $31.33 \pm 0.76$ & $p=0.079$ \\
Male & $32.29 \pm 1.86$ & $29.86 \pm 1.48$ & $p=0.307$ \\
Female & $36.29 \pm 2.44$ & $32.34 \pm 0.75$ & $p=0.076$ \\
PANSS & $122.30 \pm 4.67$ & - & - \\
Male & $128.29 \pm 3.55$ & - & - \\
Female & $117.33 \pm 7.89$ & - & - \\
BMI & $22.56 \pm 0.74$ & $23.00 \pm 0.52$ & $p=0.62$ \\
Male & $24.60 \pm 1.30$ & $23.97 \pm 0.86$ & $p=0.68$ \\
Female & $20.91 \pm 0.67$ & $22.34 \pm 0.64$ & $p=0.14$ \\
Education (years) & 12.67 & & \\
Duration of illness (years) & $7.64 \pm 0.84$ & - & - \\
TrkB (pg/ml) & $399.99 \pm 80.07$ & $663.56 \pm 77.33$ & $\mathrm{~F}=8.34$ \\
& & & $p=0.005 *$ \\
Male & $495.71 \pm 135.73$ & $741.75 \pm 129.35$ & $\mathrm{~F}=0.94$ \\
& & & $p=0.338$ \\
Female & $322.50 \pm 94.12$ & $609.80 \pm 96.07$ & $\mathrm{~F}=5.219$ \\
& & & $p=0.027 *$ \\
\hline
\end{tabular}

Data are presented as mean \pm SD. Student's $t$-test was used to compare age, PANSS, and BMI. Chi-square test was used to compare sex. TrkB analysis is performed by using an analysis of covariance (ANCOVA) with age adjustment. Abbreviations: PANSS: Positive and negative syndrome scale; BDNF: Brain-derived neurotrophic factor; BMI: Body mass index; TrkB: Tropomyosin receptor kinase $\mathrm{B} ;{ }^{*} p<0.05$, patients and controls, respectively $(\mathrm{F}=5.219, p=0.027)$, but not in men $(\mathrm{F}=0.94, p=0.338)$.

\section{DISCUSSION}

The present study investigated TrkB levels in the serum and their relationship to psychopathology in schizophrenia patients. The key findings from the study are as follows: 1. Though TrkB was thought to function as a surface protein, it is detectable in serum and its serum levels are significantly different between schizophrenia patients and healthy controls. 2. BDNF protein levels were no different in schizophrenia patients compared to healthy controls, although protein levels of TrkB were low in this group. These data indicate defective serum TrkB protein in schizophrenia patients for the first time.

There is an important implication in the findings of this study for the possible pathology and treatment of schizophrenia. The present study gives direct evidence that changes in BDNF/TrkB signaling are not only affected by the changing levels of surface receptor. Extracellular receptor protein also plays an important role. One study reported a 44\% reduction of TrkB in hippocampal extracts from schizophrenia patients. ${ }^{[12]}$ Significant diminished expression of TrkB mRNA in the large neurons of schizophrenia patients as compared to controls was also reported. ${ }^{[14]} \mathrm{How}$ ever, two studies showed no decrease in full-length TrkB expression. ${ }^{[19,20]}$ The inconsistent results with regard to the levels of TrkB lead to the suggestion that further mechanistic studies are needed to understand BDNF/TrkB signaling in schizophrenia.

The negative result in BDNF level difference between schizophrenia patients and healthy controls is inconsistent with some previous findings. Serum BDNF concentration in schizophrenia has controversial data. Some studies reported negative finding in serum BDNF levels in schizophrenia patients compared with healthy volunteers, ${ }^{[2]}$ while other studies found significant decreases in total or truncated BDNF protein levels. ${ }^{[21,22]}$ Reduced BDNF is not specific to schizophrenia. Some confounding factors such as depressive status, antipsychotic drugs, extrapyramidal symptoms, and tardive dyskinesia may affect the level of BDNF. ${ }^{[23,24]}$

Another interesting finding is the gender difference. A similar finding was reported in our previous study in which it was found that TrkB levels in women were increased significantly during depression. ${ }^{[15]}$ This study presents a significant decrease in TrkB levels in female schizophrenia patients. Sex hormones may play a role in the pathogenesis of schizophrenia. ${ }^{[25,26]}$ The distribution of phosphorylated TrkBs was found to be affected by estradiol levels. ${ }^{[27]}$ However, the real mechanism of estrogen that influences TrkB protein is still unknown.

The mechanism underlying the elevated TrkB serum 
protein level in schizophrenia patients compared to controls is not known. There are many factors that affect the level of extracellular protein, including degradation and retro-translocation. ${ }^{[28,29]}$ The reason why TrkB could be found in serum is unknown. The function of translocon or direct interactions between protein and lipid are a possible mechanism. ${ }^{[30,31]}$

Among the limitations of this work, we should underscore the following. To begin with, truncated TrkB receptors were reported to have dominant inhibitory effects on BDNF signaling. ${ }^{[32]}$ Increased truncated TrkB receptors may contribute to reduced overall BDNF/TrkB signaling and lead to reduced neuronal plasticity. ${ }^{[33]}$ However, we are only investigating total TrkB protein level. Besides, the sample size is too small, therfore analyses with larger sample sizes and better methodology are needed.

Taken together, the findings from the present study give evidence to the importance of the appropriate serum protein level of TrkB in schizophrenia patients. Decreased expression of TrkB in serum indicates the possibility that TrkB signaling impairment in schizophrenia is not at the level of neurotrophin supply, but rather at the level of the TrkB receptor being secreted in the serum. Determination of cell surface and serum TrkB receptor ratios may help in designing novel therapeutic strategies based on BDNF signaling in schizophrenia. In addition, the sample size was small in this study. A larger sample size and proper control groups are necessary to investigate and elucidate the relationships between serum TrkB protein levels and the different stages of schizophrenia in the future.

\section{Acknowledgment}

This work was supported by three clinical research grants from Chang Gung Memorial Hospital (NMRPG860231, CMRPG870952, CMRPG870951) in Taiwan.

\section{REFERENCES}

1. Harrison PJ, Weinberger DR. Schizophrenia genes, gene expression, and neuropathology: On the matter of their convergence. Mol Psychiatry 2005; 10:40-68.

2. Huang TL, Lee CT. Associations between serum brain-derived neurotrophic factor levels and clinical phenotypes in schizophrenia patients. J Psychiatr Res 2006;40:664-8.

3. Domenici E Willé DR, Tozzi F, Prokopenko I, Miller S, McKeown A, et al. Plasma protein biomarkers for depression and schizophrenia by multi analyte profiling of case-control collections. PLoS One 2010;5:e9166.

4. Schwarz E, Guest PC, Rahmoune H, Harris LW, Wang L, Leweke FM, et al. Identification of a biological signature for schizophrenia in serum. Mol Psychiatry 2012;17:494-502.

5. Buckley PF, Pillai A, Howell KR. Brain-derived neurotrophic factor: Findings in schizophrenia. Curr Opin Psychiatry 2011;24:122-7.

6. Chen CC, Huang TL. Effects of antipsychotics on the serum BDNF levels in schizophrenia. Psychiatry Res 2011;189:327-30.

7. Durany N, Michel T, Zöchling R, Boissl KW, Cruz-Sánchez FF, Riederer $\mathrm{P}$, et al. Brain-derived neurotrophic factor and neurotrophin 3 in schizophrenic psychoses. Schizophr Res 2001;52:79-86.

8. Iritani S, Niizato K, Nawa H, Ikeda K, Emson PC. Immunohistochemical study of brain-derived neurotrophic factor and its receptor, TrkB, in the hippocampal formation of schizophrenic brains. Prog Neuropsychopharmacol Biol Psychiatry 2003;27:801-7.

9. Green MJ, Matheson SL, Shepherd A, Weickert CS, Carr VJ. Brain-derived neurotrophic factor levels in schizophrenia: A systematic review with meta-analysis. Mol. Psychiatry 2011;16:960-72.

10. Toyooka K, Asama K, Watanabe Y, Muratake T, Takahashi M, Someya $\mathrm{T}$, et al. Decreased levels of brain-derived neurotrophic factor in serum of chronic schizophrenic patients. Psychiatry Res 2002;110;249-57.

11. Pillai A. Brain-derived neurotropic factor/TrkB signaling in the pathogenesis and novel pharmacotherapy of schizophrenia. Neurosignals 2008;16:183-93.

12. Takahashi M, Shirakawa O, Toyooka K, Kitamura N, Hashimoto T, Maeda K, et al. Abnormal expression of brain-derived neurotrophic factor and its receptor in the corticolimbic system of schizophrenic patients. Mol Psychiatry 2000;5:293-300.

13. Hashimoto T, Bergen SE, Nguyen QL, Xu B, Monteggia LM, Pierri JN, et al. Relationship of brain-derived neurotrophic factor and its receptor TrkB to altered inhibitory prefrontal circuitry in schizophrenia. J Neurosci 2005;25:372-83.

14. Weickert CS, Ligons DL, Romanczyk T, Ungaro G, Hyde TM, Herman MM, et al. Reductions in neurotrophin receptor mRNAs in the prefrontal cortex of patients with schizophrenia. Mol Psychiatry 2005;10:637-50.

15. Hung YY, Lin CJ, Huang TL. Higher serum tropomyosin-related kinase B protein level in major depression. Prog Neuropsychopharmacol Biol Psychiatry 2010;34:610-2.

16. First MB, Gibbon M, Sptizer RL, Williams JB. User's Guide for the Structured Clinical Interview for DSM-IV Axis I Disorders-Clinician Version (SCID-CV). Washington, DC: American Psychiatric Press; 1997.

17. Kay SR, Fiszbein A, Opler LA. The positive and negative syndrome scale (PANSS) for schizophrenia. Schizophr Bull 1987;13:261-76.

18. Chong MY, Wilkinson G. Validation of 30- and 12-item versions of the Chinese health questionnaire (CHQ) in patients admitted for general health screening. Psychol Med 1989;19:495-505.

19. Pillai A, Mahadik SP. Increased truncated TrkB receptor expression and decreased BDNF/TrkB signaling in the frontal cortex of reeler mouse model of schizophrenia. Schizophr Res 2008;100:325-33.

20. Dunham JS, Deakin JF, Miyajima F, Payton A, Toro CT. Expression of hippocampal brain-derived neurotrophic factor and its receptors in Stanley consortium brains. J Psychiatr Res 2009;43:1175-84.

21. Baig BJ, Whalley HC, Hall J, McIntosh AM, Job DE, Cunningham-Owens DG, et al. Functional magnetic resonance imaging of BDNF val66met polymorphism in unmedicated subjects at high genetic risk of schizophrenia performing a verbal memory task. Psychiatry Res 2010;183:195-201.

22. Carlino D, Leone E, Di Cola F, Baj G, Marin R, Dinelli G, et al. Low serum truncated-BDNF isoform correlates with higher cognitive impairment in schizophrenia. J Psychiatr Res 2011;45:273-9. 
23. Rizos EN, Papadopoulou A, Laskos E, Michalopoulou PG, Kastania A, Vasilopoulos D, et al. Reduced serum BDNF levels in patients with chronic schizophrenic disorder in relapse, who were treated with typical or atypical antipsychotics. World J Biol Psychiatry 2010;11:251-5.

24. Rojas PS, Fritsch R, Rojas RA, Jara P, Fiedler JL. Serum brain-derived neurotrophic factor and glucocorticoid receptor levels in lymphocytes as markers of antidepressant response in major depressive patients: A pilot study. Psychiatry Res 2011;189:239-45.

25. Castle D, Sham P, Murray R. Differences in distribution of ages of onset in males and females with schizophrenia. Schizophr Res 1998;33:179-83.

26. Riecher-Rössler A, Häfner H, Stumbaum M, Maurer K, Schmidt R. Can estradiol modulate schizophrenic symptomatology? Schizophr Bull 1994;20:203-14.

27. Spencer-Segal JL, Waters EM, Bath KG, Chao MV, McEwen BS, Milner TA. Distribution of phosphorylated TrkB receptor in the mouse hippocampal formation depends on sex and estrous cycle stage. J Neurosci 2011;31:6780-90.

28. Liao HJ, Carpenter G. Role of the Sec61 translocon in EGF receptor trafficking to the nucleus and gene expression. Mol Biol Cell 2007; 18:1064-72.

29. Xu X, Yang H, Lin YF, Li X, Cape A, Ressler KJ, et al. Neuronal Abelson helper integration site-1 (Ahi1) deficiency in mice alters TrkB signaling with a depressive phenotype. Proc Natl Acad Sci USA 2010;107:19126-31.

30. Hessa T, Kim H, Bihlmaier K, Lundin C, Boekel J, Andersson H, et al. Recognition of transmembrane helices by the endoplasmic reticulum translocon. Nature 2005;433:377-81.

31. Matteï PJ, Faudry E, Job V, Izoré T, Attree I, Dessen A. Membrane targeting and pore formation by the type III secretion system translocon. FEBS J 2011;278:414-26.

32. Eide FF, Vining ER, Eide BL, Zang K, Wang XY, Reichardt LF. Naturally occurring truncated trkB receptors have dominant inhibitory effects on brain-derived neurotrophic factor signaling. J Neurosci 1996;16:3123-9.

33. Wong J, Rothmond DA, Webster MJ, Shannon Weickert C. Increases in two truncated TrkB isoforms in the prefrontal cortex of people with schizophrenia. Schizophr Bull 2013;39:130-40. 